(С) С.Д. Колдман

\title{
ЭТИЧЕСКИЕ ПРЕПЯТСТВИЯ ПРИМЕНЕНИЯ КУКЛОТЕРАПИИ ПРИ ДЕМЕНЦИИ И БОЛЕЗНИ АЛЬЦГЕЙМЕРА*
}

\begin{abstract}
В статье поднимается вопрос об эффективности и этичности метода куклотерапии для пожильх людей, страдающих снижением когнитивных функций. Результать исследований сочииологов и медицинских антропологов, отзывы ухаживающего персонала и родственников людей, страдающих деменцией и болезнью Альцигеймера, подтверждают, что кукль облегчают прием ими лекарств, улучшают настроение и помогают повседневному взаимодействию. В поле дискуссий - вопрос об этичности метода куклотерапии в виду возможного унижения и дегуманизации пожильх людей. Данное исследование выявляет особенности восприятия куклотерапии как метода нефармакологического воздействия в уходе за пожильми людьми.
\end{abstract}

Ключевые слова: куклотерапия, деменция, болезнь Альи̧геймера, медицинская антропология, биоэтика

Согласно текущим исследованиям, в мире проживают около 50 млн чел. с деменцией (Деменция 2019). В условиях сохранности жизней, благодаря медицине и обеспечению безопасной среды, количество пожилых людей в обществе неуклонно растет. Ожидается, что к 2030 г. число лиц, подверженных дегенеративным состояниям, увеличится до 66 млн чел., а к 2050 году может достичь 115 млн (Batsch, Mittelman 2012).

Для проявлений деменции характерна потеря памяти, снижение коммуникативных навыков, агрессия, повышенная тревожность. Эти негативные проявления, кроме лечения медикаментозно, требуют дополнительных способов повышения комфорта жизни пациента в домашних условиях и во время пребывания в пансионате или доме престарелых. Среди нефармакологических видов лечения есть зарекомендовавшие себя арт-терапия, звуко-терапия, канистерапия и др., а также новые, малоизученные, например, куклотерапия. Данный метод существует около двадцати лет и уже введен в практику ухода. Различные виды терапии изучаются медицинскими антропологами с целью выявления наиболее успешных принципов здоровьесбережения, в т.ч. для улучшения состояния людей, находящихся в бессознательном или полусознательном состоянии. Работа с пожилыми людьми и фокус на болезнях, характерных для старшего возраста, позволяют разрабатывать новые методы превентивной медицины, и, тем самым, способствовать продлению активной жизни человека.

Колдман Северина Дановна - к.и.н., старший научный сотрудник, Институт этнологии и антропологии РАН (119991 Москва, Ленинский просп., 32a). Эл.почта: sev.koldman@yahoo. com. Koldman, Severina D. - PhD in Hist., Institute of Ethnology and Anthropology RAS (Moscow, Russia). E-mail: sev.koldman@yahoo.com

* Публикуется в соответствии с планом научно-исследовательских работ Института этнологии и антропологии РАН 
В целом, научные исследования антропологии игры и игрушек проводили многие антропологи и этнографы. В контексте данной темы следует упомянуть И.А. Морозова, написавшего целый ряд трудов об играх в сравнении с ритуалами (Морозов 2001), о роли куклы в игровом пространстве человека (Морозов 2011), он также выразил свой взгляд на современные виды игр, трансформацию личности в ходе игрового процесса и интерпретировал их. Кроме И.А. Морозова темой кукол и игры занимаются антропологи и этнографы М.Л. Бутовская, Н.Л. Пушкарева, И.С. Слепцова (Кызласова), А.П. Липатова, Ю.Н. Феденок, и другие. Однако в их исследованиях нет упоминаний взаимодействия с куклами людей пожилых, переживающих дегенеративные процессы в области когнитивных функций.

Целью данной статьи является постановка проблемы, касающейся этической приемлемости куклотерапии для пожилых людей, страдающих снижением когнитивных функций, и экономических препятствий ее применения. В работе использованы сравнительный и опросный методы. Привлечены материалы экспериментов, проводимых в Великобритании, Австралии, США и Корее, о результатах применения куклотерапии в пансионатах и в домашней обстановке, и об этичности метода. Кроме того, использованы сведения двух интервью: с президентом одного из российских фондов, задачей которого является информирование заинтересованных лиц о болезни Альцгеймера, а также о разработке рекомендаций по уходу за пожилыми людьми (декабрь 2019 г.), и с дочерью пожилой женщины, которая на протяжении не менее 15 лет страдала от снижения когнитивных функций (официальный диагноз «деменция») (январь 2020 г.).

\section{Куклотерапия в исследованиях}

Из книг, новостных лент, специализированных форумов и видеороликов на Yоutube известно о глубокой привязанности некоторых долгожителей (около ста лет, и больше) к куклам. На сайте «Клуб 101-летних» рассказана история Мари Энн Дрезден, умершей в возрасте 109 лет и 213 дней (дата смерти: 6 июня 2011 г.), которая являлась коллекционером кукол (Marie Ann Demuth... 2015). Мари была самой старшей из восьмерых детей у своих родителей и позже стала матерью одного сына, бабушкой троих внуков и дважды прабабушкой. Верификация сведений о возрасте была подтверждена переписью населения 1910 и 1920 гг. В штате Вашингтон умерла вторая в списке долгожителей штата 114-летняя Эмма Оттис. В данном случае в новостях подчеркивалось, что Эмму нашли обнимающей любимую куклу-скаута (In memory of Emma Otis... 2015). Близкие описывают, что Эмма стояла у истоков создания и развития движения девочек-скаутов, которому она посвятила всю свою жизнь.

Интересно, что долгожительницы интересовались именно куклами, предметами антропоморфной формы, а не мягкими игрушками, хотя заинтересованность ими не исключение. Эксперимент в Великобритании (Ньюкасл) показал, что 93\% людей, принявших участие в игре, предпочли кукол плюшевым мишкам (James, Mackenzie, Mukaetova-Ladinska 2006). Такой интерес к куклам, проявивший себя на практике, стал предметом изучения. В зарубежных научных трудах опубликованы данные экспериментов с куклами в домах для престарелых, или в домашней обстановке (Ellingford и др. 2007; Juh Hyun Shin 2015; Bisiani, Angus 2013). Эксперимент заключался в том, чтобы изучить состояние пансионеров, принимавших нейролептиче- 
ские препараты на протяжении трех месяцев до начала эксперимента с куклами и трех месяцев после введения кукол в повседневную жизнь пожилых людей. В фокусе исследователей находились пансионеры, добровольно выбравшие кукол, а также те, кто не проявил к ним никакого интереса (контрольная группа), или же у которых заинтересованность куклами была кратковременной. По договоренности с авторами эксперимента ухаживающий персонал ежедневно фиксировал поведение пожилых людей, что позволяло соотносить эти данные с дозировкой препаратов. В результате эксперимента коллектив ученых пришел к выводу, что у пожилых людей, использующих кукол, улучшилось настроение и снизились случаи агрессивного поведения, повысилась опрятность пациентов и увеличилась их физическая активность. На медикаментозное лечение данная терапия оказала малый эффект - дозировки нейролетиков снизились на 1\% (Fernandez, Arthur, Fleming, Perrin 2014: 12), однако улучшение касалось только тех, кто выбрал кукол.

Похожий эксперимент был проведен в Австралии с участием 35 человек, с которыми кто-нибудь приходил играть в куклы на протяжении 30 минут в течение трех недель (индивидуальные сессии интенсивностью 1 раз в неделю). Результат эксперимента не выявил высокой эффективности куклотерапии по сравнению с обычным уходом (Moyle, Murfield, Jones, Beattie, Draper, Ownsworth 2019). Однако у принимавших участие в игре с куклой отмечалось улучшение настроения (ощущение удовольствия). Персонал подтвердил появление эмоционального комфорта у пациентов. В данном исследовании отсутствует опыт самостоятельного взаимодействия респондента с куклой, естественного и закрытого от посторонних, что, возможно, и стало причиной низкой эффективности метода. Часть экспериментов, посвященных куклотерапии в уходе за пожилыми людьми с деменцией или болезнью Альцгеймеpa, была подвержена критике (Mitchell, McCormack, McCance 2016).

\section{Вопрос этики}

Куклотерапия попала в категорию «этически спорных» методов нефармакологической коррекции возбужденных состояний у пожилых людей (Andrew, 2006). Высказывается мнение, что данный метод способствует развитию «ложных иллюзий» $(B i-$ siani, Angus, 2013: 449). В дискуссиях о куклотерапии употребляется словосочетание «белая ложь», подразумевающее осознанный обман людей, страдающих деменцией с целью облегчения процессов лечения и взаимодействия с ними (Schermer 2007; Tuckett 2010). У исследователей возникает вопрос, является ли куклотерапия терапевтической привилегией, и имеют ли пациенты «право на правду» (Richard, Lajeunesse, Lussier 2010)? Кроме того, прозвучали такие определения как «дегуманизация» в контексте представлений о впадении пациента во второе детство, что противникам метода представляется оскорблением личности (Hughes, Louw, Sabat 2006).

На одном из российских форумов, посвященных обсуждению проблем пожилых и рекомендаций по уходу за престарелыми родителями с деменцией, одна из участниц привела положительный опыт своей мамы от взаимодействия с куклами. Ответный комментарий одного из администраторов сайта был следующим: «Недавно разговаривал с психологом, который говорит, что нельзя относиться к больному как к ребенку. Это одна из самых распространенных ошибок. Люди рассуждают так: “Раз он разум теряет и превращается в несмышленого, как ребенок, человека, то надо 
с ним соответственно общаться”. И это ошибка. Вспомнил об этом, когда прочитал про кукол (Чем занять больную... 2013).

Участница дискуссии рассказала о собственном опыте, в котором она наблюдала самостоятельную смену статуса пожилым человеком со взрослого на ребенка: «Даже не дементный отец ближе к смерти очень любил эдак “впасть в детство”, чтобы с ним как с маленьким повозились, и самоумилялся этому, хотя при активной жизни был человек грубый и черствый. А мать - так та вообще говорила, что, мол, раньше она была старшая, а теперь она младшая, и с ней надо как с младшей, и с удовольствием перебирала всякие детские предметы» (Там же).

Для подтверждения или опровержения предположения о сознательном или бессознательном «впадении в детство» следовало бы провести качественный эксперимент с людьми, проживающими в российских условиях. Рынок игрушек предлагает множество изделий, имеющих распространение в странах мира, однако лишь в России существует такая категория игрушек как «советская кукла». На данный момент пожилыми людьми являются те, чье детство приходилось на ранний советский период и промышленную революцию в куклопроизводстве. А именно: переход от интерьерной «буржуазной» куклы к куклам - представителям профессий, куклам персонажам сказок, широко распространенным благодаря массовому производству по Советскому Союзу. Несмотря на критику качества изделий: хрупкого и выцветающего пластика, плохой детализации конечностей, частому отсутствию белков глаз и других издержек массового производства, данные куклы являлись партнерами по играм у советских детей. При повторении исследования о влиянии куклотерапии на поведенческие расстройства и когнитивные способности пожилых людей, страдающих деменцией и болезнью Альцгеймера, следовало бы ввести в обиход советских кукол. Данные куклы не обладают яркой мимикой и правильными человеческими пропорциями, не имеют четкой идентификации и не отличаются высоким качеством пластика, что могло бы способствовать тактильному удовольствию играющего. И в случае проявления интереса участниками эксперимента к такой кукле, можно было бы предположить мысленное возвращение человека, подверженного дегенеративным состояниям, в его собственное детство.

Данное предложение о повторении эксперимента зарубежных исследователей куклотерапии в каком-либо российском пансионате, или доме для престарелых, было высказано президенту фонда (его имя, а также название фонда не указываются), занимающегося распространением информации о болезни Альцгеймера и способах ухода за больными; с ее стороны выявилось остро негативное отношение к куклам и, следовательно, к куклотерапии. В ходе беседы президент фонда перешла к таким опровергающим метод куклотерапии аргументам как: 1) кукла для старика, страдающего деменцией или болезнью Альцгеймера, является предметом небезопасным (например, существует возможность откусить глаза у игрушки и подавиться ими, или ударить куклой соседа по палате); 2) чтобы провести исследование, аналогичное зарубежным, и предложить кукол в дом престарелых, или родственникам пожилого человека, необходимо разработать проект с указанием взаимной выгоды этого для исследователей и для фонда, подготовить информативные раздаточные материалы, из которых станет понятно, что представляет собой «куклотерапия» как продукт, и каким образом его продвигать (ПМА 1). По мнению руководителя фонда, в идее повторить эксперимент есть ряд трудноразрешимых вопросов. Например, каким образом будет происходить 
информирование об услуге, где брать контакты, действительно ли следует подписывать с родственниками и/или опекунами документ о согласии на проведение куклотерапии (рекомендовано в аналогичных исследованиях - прим. автора), а также уведомление о том, что куклотерапия не является фармакологическим лечением. Также было высказано замечание, что организация подобного исследования может повлечь за собой проблемы и споры о собственности: кто станет приобретателем кукол, и кто впоследствии окажется их владельцем (пансионат, пожилой человек, благотворитель, исследователь). В случае размещения кукол на территории пансионата или дома престарелых игрушкой может заинтересоваться тот, чьи родственники высказались против использования куклотерапии. Каким образом следует поступать в таком случае, следует ли отбирать куклу у пациента. В результате руководитель фонда признал проведение куклотерапии для российских пациентов нецелесообразным: «Раскраски - это мне понятно, ну еще мягкие игрушки, куда ни шло... Но куклы!.. Не знаю» (ПМА 1).

В книге, посвященной опыту применения куклотерапии, Дж. Корриган-Чарльзворт отмечает, основываясь на его 27-летней практике работы с людьми с деменцией: «Лично я никогда не сталкивался с терапией, которая вызвала бы такой широкий резонанс обсуждений» (Baker, Corrigan-Charlesworth 2007: 90). При этом, как нам кажется, данная терапия не отличается принципиально от просьб к пожилому человеку раскрасить детские раскраски, или собрать цветные кубики.

Остро негативное отношение наблюдается как со стороны родных, часто людей среднего возраста, так и со стороны пожилых. По заявлению 95-летней москвички, данный метод терапии представляется пугающим: «Это ужасно! Это неестественно! Люди сошли с ума!» (из материалов автора). Действительно, в большинстве устных отзывов о куклотерапии и куклах, высказанных людьми разного возраста, образования и опыта, прозвучали такие слова: «звучит пугающе», «страшно», «я их боюсь». Некоторые родственники пожилых людей считают, что пользование куклами «унижает» их родителей. В одном видео в социальных сетях, отражающем общение 94-летней Джесси Болл с любимой куклой-младенцем, комментарии были разнообразными, в том числе негативными: «А пожилым женщинам бы это понравилось, что вы делаете с ними? Надо сохранить их достоинство!» (Пожилая британка... 2017). Однако сама автор видео, дочь пожилой Джесси, считает, что этот сюжет о ее маме вдохновит других людей отдавать даром куклы в дома престарелых.

Исследование куклотерапии как метода коррекции агрессивного поведения и стимулирования когнитивных функций у пожилых людей, страдающих деменцией и болезнью Альцгеймера, наравне с арт-терапией, аромо-терапией и другими, не предполагает создание какого-либо «продукта» и дальнейшего его продвижения. Автор статьи отдает себе отчет, что одной из приоритетных задач фонда является привлечение средств благотворителей и поиск различных способов заработка, в том числе путем продажи оригинальных идей, связанных с уходом за пожилыми людьми. Однако именно куклотерапия не показалась привлекательной с точки зрения выгоды, несмотря на ее практическую состоятельность и научную обоснованность.

Куклы для данного вида терапии уже были разработаны заинтересованными лицами, и их продвижение строится на отзывах потребителей (Joy For All... 2015). Так, сообщество Dementia Society of America, являющееся активным распространителем обучающей информации о деменции и болезни Альцгеймера, объявило золотым призером в номинации Dementia SMART компанию «Joy For All Companion Pets» по про- 
изводству специальных игрушек для пожилых людей. Однако производимые компанией интерактивные игрушки в виде домашних питомцев (кошка и щенок) на вид и по функционалу не отличаются от игрушек аналогичной категории, предназначенных для детей, что позволяет в куклотерапии использовать любые игровые предметы.

Дж. Корриган-Чарльзворт обратил внимание, что к наиболее распространенным выявленным потребностям человека, страдающего деменцией, относятся потребности в комфорте, в привязанностях, вовлеченности (включенности), занятиях и идентичности (Baker, Corrigan-Charlesworth 2007: 91). Анализ результатов экспериментов куклотерапии выявляет отмеченное исследователями и ухаживающим персоналом смягчение чувства одиночества у тех респондентов, кто выбрал куклу, а также снижение у них уровня тревожности, возникновение занятости, появление цели, что соответствует представлениям об эффективности практики.

Следует отметить, что введение кукол в повседневный обиход пожилого человека строго добровольно. Кукол рассаживают в различных местах в доме или пансионате, на диванах и скамейках, где они могут привлечь внимание. Однако за привлечением внимания (или его отсутствием) стоит самостоятельное решение человека взять куклу, потрогать и вернуть обратно, или унести к себе и проводить с ней время. Дискуссии вокруг куклотерапии привели к тому, что Комиссия по этике обратила внимание на данный вопрос и вынесла заключение, что заказчиком услуг в этих случаях являет сам пациент (Mitchell, Templeton 2014: 727-728). Авторы книги, имеющие длительный опыт работы с дементными людьми, комментируют практику куклотерапии: «Человек наслаждается, и кто мы такие, чтобы усомниться в целесообразности этого?» (Baker, Corrigan-Charlesworth 2007: 90).

\section{Частная практика}

В ходе исследования удалось получить сведения от человека, который на протяжении длительного времени наблюдал взаимодействие своей мамы с куклой и иными антропоморфными изображениями. Мама респондента Н.Н. (инициалы имени изменены по просьбе респондента) 1930 года рождения, из интеллигентной среды, страдала снижением когнитивных функций на протяжении многих лет (с начала 2000-х). Развитие деменции семья заметила не сразу, и одним из маркеров заболевания стал повышенный интерес мамы к игрушкам своей внучки, а именно к куклам.

Поначалу мама стала их доставать из места, где куклы хранились, и усаживать на диван, затем у кукол появились одежда и украшения. Родные сочли данное увлечение скучанием по внукам, но постепенно комната мамы наполнилась куклами, и попытки спрятать их вызывали протест с ее стороны. При этом мама не разрешала Н.Н. наблюдать за ее общением с куклой, выгоняла из комнаты и даже иногда кричала. Н.Н. пыталась подслушивать, но мама проявляла невероятную хитрость: «Это были ее отношения... Она относилась к куклам очень серьезно» (ПМА 2). Сначала у кукол были имена, но постепенно в процессе деперсонификации, имена переставали иметь значение: «Она говорила “Ее звали Кукла” - это имя». Для Н.Н. был очевиден процесс размытия семантических границ, и так как домашние называли куклу «куклой», мама Н.Н. стала использовать это слово в качестве имени.

В своих рассуждениях о возможной причине такой заинтересованности куклами, Н.Н. предположила несколько версий: а) кукла стала симулякром образа дочери, б) кукла позволяла маме восполнять чувство утраты своей матери, 3) таким образом 
выразилась потребность избегать того количества информации, какая исходит от живых людей. По мнению Н.Н., взаимодействие с антропоморфным предметом своего рода самопомощь, интуитивное отсекание лишнего, что пожилому человеку, страдающему угасанием когнитивных функций, возможно, было сложно обрабатывать. «Она создала для себя какие-то референтные точки, которые стали для нее зоной комфорта... Возможно, она боялась совершить какой-то ошибочный шаг. <...> И вот в эту зону комфорта попали куклы» (ПМА 2).

По наблюдениям родственников, взаимодействие с куклами не является неосознаваемым постоянно. Кроме того, имеет место улучшение речи и возникает разнообразие интонаций в периоды общения с куклами, а также создание особой приватной, доверительной обстановки, которой по какой-то причине не хватает больному.

Травма потери матери никогда не отпускала маму Н.Н., что проявлялось в моменты конфликтов, когда мама заявляла: «Ты не понимаешь, как это, когда у тебя мать есть». Для нее наличие матери было наивысшей ценностью. Однако была ли иерархичность в отношении с куклой, Н.Н. не удалось выяснить. Надо отметить, что убежденность пожилых людей в том, что их родители все еще живы, рассматривается в науке в контексте травмы потери, которая в том числе способствует ощущению небезопасности. Также высказывается предположение, что заболевание деменцией - это результат такого опыта потери, основанный на глубокой привязанности к умершим (Miesen 1993; Osborne, Stokes, Simpson 2010), представлявшим авторитет. Теория привязанности Дж. Боулби также рассматривается в науке, как возможное объяснение эффективности куклотерапии (Minshull 2009).

В ходе интервью Н.Н. вспоминала, что мама играла с ней очень мало ввиду своей занятости и занимаемой высокой должности, но те несколько раз, когда она играла, она говорила: «Запомни, что я с тобой играла».

Тяжелым опытом для Н.Н. стала смена ролей мать - ребенок, во время болезни мамы она испытывала стыд за ее увлечение куклами, однако со временем, по ее словам, наносные общественные стереотипы отпали сами собой, и осталась только проблема заболевания и любовь к матери. Сейчас Н.Н. считает, что необходимо распространить информацию о куклотерапии как методе, способствовать изменению отношения взрослых людей к куклам, как предмету, дающему чувство защищенности и комфорта их пожилым родителям. Что касается личного отношения Н.Н. к самому предмету - кукле, она призналась: «Это было непросто принять, учитывая, что мама была человеком высокоинтеллектуальным... И такое ее внимание к куклам воспринималось с каким-то таким чувством почти стыда». Постепенно, в процессе болезни мама, по оценке Н.Н., стала вести себя как пятилетний ребенок. Н.Н. предполагает, что это стало определяющим в выборе кукол. Так, мама полностью потеряла интерес к куклам, изображающим взрослых и подростков, и предпочла «пупсоподобных» кукол.

Аналогичную точку зрения высказали специалисты: «Использование кукол иногда трудно понять или принять родственникам человека, живущего с деменцией. Однако это может быть связано с недостаточным информированием со стороны (ухаживающего, медицинского - С.К.) персонала» (Baker, Corrigan-Charlesworth 2007: 90). Имеющий многолетний стаж в уходе за людьми, страдающими снижением когнитивных функций, Г. Миттчел также отмечает недостаточное информирование о куклотерапии со стороны государства и благотворительных организаций, а также слабое распространение практических рекомендаций (Mitchell 2006: 14). 
Н.Н. обратилась к изучению профессиональной литературы о болезни, из которой узнала, что человек перестает различать симулякры и оригиналы. Например, мама могла купить пластиковые цветы и поставить их в воду, как живые. Или на прогулке она иногда останавливалась у витрины магазина и говорила с манекеном. В маршрут прогулок по городу входил сквер, где находилась статуя Ленина в человеческий рост, антропоморфное изображение из бронзы. Мама Н.Н. покупала конфеты и пряники, подходила к нему и разговаривала. Нередко она не хотела, чтобы Н.Н. присутствовала при этих разговорах, и тогда Н.Н. наблюдала издалека. Она заметила, что при разговоре со статуей мама держала зрительный контакт, обращалась по имени-отчеству с эпитетами «дорогой мой», рассказывала, как у нее дела. Мама ненадолго отходила от статуи, и за это время вороны успевали расклевать конфеты и пряники, так что по возвращении мама радовалась тому, что В.И. Ленин попробовал ее угощение.

Н.Н. решила сделать кукол мамы своими помощниками и стала использовать их в качестве «товарищей» по еде и приему лекарств: «Она отказывалась принимать лекарства, и вот этот классический способ “у зайчика заболи, у волчка заболи, а у кого-то заживи... ложечку за папу, ложечку за Машу.... В принципе, когда лекарство она отказывалась принимать, и иной раз удавалось ее убедить принимать лекарство именно вот привлекая в сообщники кукол» (ПМА 2).

Аналогичный опыт применения куклы для облегчения приема пищи и лекарств у пожилого человека, страдающего деменцией, описан в книге Г. Миттчела, наблюдавшего за взаимодействием с куклой пожилой женщины по имени Клара (Mitchell 2006: 14). На основании своего исследовательского опыта Г. Миттчел заключает, что куклотерапия подходит не всем, а лишь тем, кто выбирает его добровольно. Опыт других исследователей говорит о том же, особенно в случае встречающегося среди пожилых пансионеров негативного родительского опыта (Baker, Corrigan-Charlesworth 2007: 91), или же на фоне приема сильнодействующих лекарств, особенно на поздних стадиях заболевания.

По прошествии более чем 15 лет, и в результате прогрессирования болезни (которое, по мнению Н.Н., напоминало инволюцию), дочь была вынуждена уступить рекомендациям врачей и поместить маму в больницу. Сведений о том, искала ли мама свою Куклу, будучи в больнице, Н.Н. не поступало.

В похожей истории с мамой Робин, куклу позволено было взять в госпиталь, где мама продолжала с ней спать по ночам (Dementia - Baby Doll Therapy... 2011).

Отношение к куклам меняется в современном обществе, поскольку игра в куклы перестает быть прерогативой детства и становится показателем материального благополучия, и символом активной, наполненной впечатлениями жизни. Куклы Barbie, Blythe и другие, становятся стильным атрибутом современного человека любого пола. Любимым куклам посвящают блоги в популярных социальных сетях, шьют или покупают дорогостоящие наряды и обувь (кожаные ботинки на Blythe стоят около 2000 руб., пальто с ручной вышивкой - около 5000 руб.), размещают фотографии из ресторанов и с туристических мест.

Об изменении отношения к куклам свидетельствуют работы таких кукольных мастеров, как Александра Соцкова (Россия, Москва) - высококачественные шарнирные изделия в виде стариков с тщательной детализацией возрастных изменений тела («брыли» на лице, деформация плеч и позвоночника, артритные суставы на руках и ногах, обвисшая кожа), с соответствующим макияжем (морщины, пигментные пят- 
на). Возможно, использование в терапии куклы, изображающей пожилого человека, дало бы представление о потребностях пожилого человека в компаньоне, тем самым расширив диапазон мнений о причинах выбора кукол среди людей, страдающих дегенеративными заболеваниями.

Ha Youtube на одном из частных каналов Робин Ван Хайнинг (Robin VanHyning) размещено видео ее мамы, страдающей деменцией, играющей в куклу фирмы «Adora». В своих комментариях к видео Робин делится предположением, что все дело в лицах кукол, а именно в улыбчивом и «счастливом» выражении некоторых молдов (кукольных лиц) (Dementia - Baby Doll Therapy 2011). Мама Н.Н. остановила свой выбор на кукле-ребенке лет пяти. Аналогичную куклу предпочитала 114-летняя Эмма Оттис. Куклы-младенцы и барбиобразные куклы такими лицами не обладают, это характерно для кукол-детей, изображающих девочек в возрасте 3-4 лет. Однако имеются видеосюжеты, посвященные куклотерапии, в которых использованы куклы-младенцы (Morning Pointe 2014; Baby Doll Therapy 2016; Passion for those affected by Dementia/Alzheimer's 2018; Two women give Alzheimer's patients 2018).

\section{Выводы}

Исследование вопроса о куклотерапии в лечении и поддержании пожилых людей, страдающих деменцией или болезнью Альцгеймера, выявляет следующие проблемы. Отсутствуют специальные методики для внедрения данного вида терапии, и не определена терминология. Несмотря на ряд проведенных экспериментов, часть специалистов считает их результаты недостоверными, поверхностными и «анекдотичными». Тем не менее, для изучения взаимодействия с антропоморфными предметами среди пожилых людей, данные «забракованных» исследований также имеют значение с точки зрения медицинской антропологии, поскольку демонстрируют методы работы с респондентом. Недостатком изучения является его непоследовательность и непродолжительность.

Нет рекомендаций относительно видов куклы, наиболее предпочтительных для данного вида терапии, а попытки производить «особенных кукол» приводят к их логистической недоступности и высокой цене. Кроме того, специальные куклы не имеют преимуществ перед обычными куклами, предназначенными для детской игры. В ходе экспериментов выявились особенности применения кукол с пищиками (издающими резкие громкие звуки, или плач), или с подвижным глазным механизмом. Есть вероятность, что страдающий деменцией человек уложит куклу спать и будет ее будить методом касания плечика, или легкой тряски. Кукла с глазным механизмом, будучи в лежачем положении, не откроет глазки, что может быть воспринято человеком как ее заболевание или смерть, это может привести к негативным последствиям.

Препятствием для активного применения куклотерапии является отсутствие достоверных знаний о действительных потребностях человека, страдающего деменцией или болезнью Альцгеймера, которую удовлетворяет кукла. Какие задачи ставит перед собой психика человека в период возрастных изменений? Какие социальные проблемы решает пожилой человек, репрезентирует ли жизненные ситуации, или же пребывает в настоящем? Какую роль он определяет для самого себя, а какую для куклы? Можно ли считать процесс игры пожилого человека наделенным дидактическим смыслом, как принято думать о детской игре? Данные вопросы тре- 
буют дополнительного специального анализа медицинскими антропологами, социальными антропологами, психологами, социологами, и другими специалистами. Результаты, по нашему мнению, будут полезны в изучении заболеваний, связанных со снижением когнитивных функций в любом возрасте, его причинах и способах лечения. Также данные эксперимента позволят понять роль куклы для человека в любом, и каждом конкретном, возрасте. Интересно определить наличие или отсутствие традиционного или мистического отношения к куклам в разных ситуациях, особенно в свете длительной сохранности традиций олицетворения куклами пожилых людей.

\section{Источники и материалы}

Деменция 2019 - Деменция. Всемирная организация здравоохранения. 14 мая 2019 г. https:// www.who.int/ru/news-room/fact-sheets/detail/dementia.

Мемини 2013 - Мемини. Чем занять больную? 15 июня 2013 г. https://memini.ru/discussions/ $24304 \#$ comment-24014.

Medialeaks 2017 - Medialeaks. Пожилая британка с деменцией путает куклу с внучкой. И история за этим видео очень трогательная. 02 ноября 2017 г. https://medialeaks.ru/0211ttptak-mozhno-pomoch-bolnyim-dementsiey-trogatelno-pugayushhee-video-babushki-i-kuklyikotoruyu-ona-schitaet-vnuchkoy.

ПМА 1 - Полевые материалы автора. Встреча с представителем фонда (название фонда и имя президента не указывается), созданного с целью информирования российского сообщества о болезни Альцгеймера, разработке и проведения лекций по уходу за пожилыми людьми для всех желающих. Декабрь 2019 г. (информант - президент фонда).

ПМА 2 - Полевые материалы автора. Интервью с дочерью пожилой женщины, которая добровольно выбрала взаимодействие с куклами, будучи в состоянии снижения когнитивных функций на протяжении нескольких лет. Январь 2020 г. (информант - Н.Н.)

Joy for all 2019 - Joy for all companion pets. https://joyforall.com/pages/our-story.

Morning Pointe 2014 - Morning Pointe Senior Living (blog). Morning Pointe Alzheimer's Residents Embrace Cuddle Therapy 2014 - Cuddle Therapy. 03 июня 2014 г. https://www.youtube.com/ watch? $=$ ozZHYfhRoPY.

Love What Matters 2018 - Love What Matters (blog). Passion for those affected by Dementia/Alzheimer’s. 16 февраля 2018 г. https://www.youtube.com/watch?v=mJHdUhNCn_s\&feature=emb_title.

\section{Научная литература}

Морозов И.А. «Игра» и «ритуал» в современном научном дискурсе // Традиционная культура. Научный альманах, 2001. № 1. С. 20-28.

Морозов И.А. Феномен куклы в традиционной и современной культуре (Кросскультурное исследование идеологии антропоморфизма). М.: Индрик, 2011.

Andrew A. The ethics of using dolls and soft toys in dementia care // Nursing \& Residential Care, 2006. № 8 (9). P. 419-421.

Baker C., Corrigan-Charlesworth J. Visiting the Memory Café and other Dementia Care Activities: Evidence-based Interventions for Care Homes. London: Jessica Kingsley Publishers, 2007.

Batsch N.L., Mittelman M.S. Alzheimer's Disease International. World Alzheimer Report 2012: overcoming the stigma of dementia. London: Alzheimer's Disease International, 2012.

Bisiani L., Angus J. Doll therapy: A therapeutic means to meet past attachment needs and diminish behaviours of concern in a person living with dementia - a case study approach // Dementia (London), 2013. Vol 12. № 12(4). P. 447-62.

Ellingford J., James I., Mackenzie L., Marsland L. Using dolls to alter behaviour in patients with dementia. Nursing Times, 2007. Vol. 103. Janury 30, 5. P. 36-37. 
Fernandez R., Arthur B., Fleming R., Perrin C. Effect of doll therapy in managing challenging behaviors in people with dementia: a systematic review // The JBI Database of Systematic Reviews and Implementation Reports, 2014. № 12 (8). P. 330-363.

James I.A., Mackenzie L., Mukaetova-Ladinska E. Doll use in care homes for people with dementia // Int J Geriatr Psychiatry, 2006. № 21: 1093-1098.

Hughes J., Louw S., Sabat S.R. Dementia: Mind, Meaning, and the Person. Oxford: Oxford University Press, 2006.

Miesen B. Alzheimer's disease, the phenomenon of parent fixation and Bowlby's attachment theory // International Journal of Geriatric Psychiatry. 1993. № 8. P. 147-153.

Minshull K. The impact of doll therapy on well-being of people with dementia // Journal of Dementia Car. 2009. № 17 (2). P. 35-38.

Mitchell G. Doll Therapy in Dementia Care: Evidence and Practice. London: Jessica Kingsley Publishers, 2006.

Mitchell G., McCormack B., McCance T. Therapeutic use of dolls for people living with dementia: A critical review of the literature // Dementia (London), 2016. Vol. 15. № 15 (5). P. 976-1001.

Mitchell G., Templeton M. Ethical considerations of dolltherapy for people with dementia // Nursing Ethics. 2014. № 21 (6). P. 720-730.

Moyle W., Murfield J., Jones C., Beattie E., Draper B., Ownsworth T. Can lifelike baby dolls reduce symptoms of anxiety, agitation, or aggression for people with dementia in long-term care? Findings from a pilot randomised controlled trial // Aging \& Mental Health. 2019. № 23. Pp. 1442-1450.

Osborne H., Stokes G., Simpson J. A psychosocial model of parent fixation in people with dementia: The role of personality and attachment // Aging \& Mental Health. 2010. № 14. P. 928-937.

Tuckett A. The experience of lying in dementia care: A qualitative study // Nursing Ethics. 2010. № 19 (1). P. 7-20.

Schermer M. Nothing but the truth? On truth and deception in dementia care // Bioethics. 2007. № 21 (1). P. 13-22.

\section{References}

Andrew A. 2006. The ethics of using dolls and soft toys in dementia care. Nursing \& Residential Care 8 (9): 419-421.

Baker C., and J. Corrigan-Charlesworth. 2007. Visiting the Memory Café and other Dementia Care Activities: Evidence-based Interventions for Care Homes. London: Jessica Kingsley Publishers.

Batsch N.L., and M.S. Mittelman 2012. Alzheimer's Disease International. World Alzheimer Report 2012: overcoming the stigma of dementia. London: Alzheimer's Disease International.

Bisiani L., and J. Angus. 2013. Doll therapy: A therapeutic means to meet past attachment needs and diminish behaviours of concern in a person living with dementia - a case study approach. Dementia (London) 12 (4): 447-462.

Ellingford J., I. James, L. Mackenzie, and L. Marsland. 2007. Using dolls to alter behaviour in patients with dementia. Nursing Times 103 (30,5): 36-37.

Fernandez R., B. Arthur, R. Fleming, and C. Perrin. 2014.Effect of doll therapy in managing challenging behaviors in people with dementia: a systematic review. The JBI Database of Systematic Reviews and Implementation Reports 12 (8): 330-363.

Hughes, J., S. Louw, and S.R. Sabat. 2006. Dementia: Mind, Meaning, and the Person. Oxford: Oxford University Press.

James, I.A., L. Mackenzie, and E. Mukaetova-Ladinska. 2006. Doll use in care homes for people with dementia. Int J Geriatr Psychiatry 21: 1093-1098.

Miesen, B. 1993. Alzheimer's disease, the phenomenon of parent fixation and Bowlby's attachment theory. International Journal of Geriatric Psychiatr 8: 147-153.

Minshull, K. 2009. The impact of doll therapy on well-being of people with dementia // Journal of Dementia Car 17 (2): 35-38. 
Mitchell, G. 2006. Doll Therapy in Dementia Care: Evidence and Practice. London: Jessica Kingsley Publishers.

Mitchell, G., and M. Templeton. 2014. Ethical considerations of dolltherapy for people with dementia. Nursing Ethics 21(6): 720-730.

Mitchell, G., B. McCormack, and T. McCance. 2016. Therapeutic use of dolls for people living with dementia: A critical review of the literature. Dementia (London) 15 (5): 976-1001.

Morozov, I.A. 2001. «Igra» i «ritual» v sovremennom nauchnom diskurse [Game and Ritual in Modern Scientific Discourse)]. Tradicionnaya kul'tura. Nauchnyj al'manah 1: 20-28.

Morozov, I.A. 2011. Fenomen kukly v tradicionnoj i sovremennoj kul'ture (Krosskul'turnoe issledovanie ideologii antropomorfizma) [The Doll Phenomenon in Traditional and Modern Culture (Cross-Cultural Study of the Ideology of Anthropomorphism)]. Moscow: Indrik.

Moyle W., J. Murfield, C. Jones, E. Beattie, B. Draper, and T. Ownsworth. 2019. Can lifelike baby dolls reduce symptoms of anxiety, agitation, or aggression for people with dementia in long-term care? Findings from a pilot randomised controlled trial. Aging \& Mental Health 23: 1442-1450.

Osborne H., G. Stokes, and J. Simpson. 2010. A psychosocial model of parent fixation in people with dementia: The role of personality and attachment. Aging \& Mental Health 14: 928-937.

Schermer, M. 2007. Nothing but the truth? On truth and deception in dementia care. Bioethics 21 (1): 13-22.

Tuckett, A. 2010.The experience of lying in dementia care: A qualitative study. Nursing Ethics 19 (1): 7-20.

Koldman, Severina D.

\section{Ethical Constraints to Application of Doll Therapy for Treating Dementia and Alzheimer's Diseases}

The article raises the question of the effectiveness and ethics of the method of doll therapy for older people suffering from a decrease in cognitive functions. The results of studies by sociologists and medical anthropologists, evidence of caring staff and relatives of people suffering from dementia and Alzheimer's disease confirm that dolls make medication easier, improve mood and facilitate everyday interaction. The subject of discussion is the question of the ethics of the doll therapy in view of possible humiliation and dehumanization of older people. This study reveals the perception of doll therapy as a method of non-pharmacological treatment in caring for the elderly.

Keywords: doll therapy, dementia, Alzheimer's disease, medical anthropology, bioethics 